\title{
Organização de recursos competitivos: análise de um hotel na cidade de Mossoró/RN
}

\section{Organization of competitive resources: analysis of a hotel in the city of Mossoró / RN}

\author{
KENNIA FERREIRA DE MACEDO BEZERRA \\ UFERSA \\ YÁKARA VASCONCELOS PEREIRA \\ UFPB \\ VIVIANE SANTOS SALAZAR \\ UFPE \\ VINICIUS FARIAS MOREIRA \\ UFCG
}

\section{RESUMO}

Os recursos disponíveis em uma empresa representam fortes aliados na geração de vantagem competitiva, desde que sejam geridos de maneira correta. O campo da gestão estratégica recebe importantes contribuições da Visão Baseada em Recursos (VBR) e esta foi a base para o surgimento do modelo VRIO que se estrutura na questão do valor, da raridade, imitabilidade e organização dos recursos. Este estudo se estrutura na organização dos recursos de uma empresa e para isso definiu-se por objetivo geral analisar a dimensão organização do modelo VRIO num hotel da cidade de Mossoró/RN. Foram realizadas entrevistas semiestruturadas com nove colaboradores de diferentes níveis hierárquicos, sendo possível perceber as visões a respeito dos recursos da empresa. Esta pesquisa seguiu uma abordagem qualitativa com caráter descritivo e foi realizada mediante estudo de caso numa empresa do setor hoteleiro da cidade de Mossoró/RN. O exame dos dados se realizou por meio da análise de conteúdo com o suporte tecnológico do software ATLAS.ti. Os resultados indicaram que a empresa possui recursos considerados valiosos, raros e de difícil imitação como o know-how, a marca e o padrão internacional. A organização destes recursos se baseia em ações voltadas para a fiscalização, gestão diferenciada de pessoas e planejamento. 
Palavras-chave: Recursos; Vantagem competitiva; Modelo VRIO; Organização dos recursos.

\section{Abstract}

The resources available in a company represent strong allies in generating competitive advantage, provided they are managed correctly. The field of strategic management receives important contributions from the Resource Based View (VBR) and this was the basis for the emergence of the VRIO model that is structured in the issue of value, rarity, imitability and organization of resources. This study is structured in the organization of the resources of a company and for this it was defined by general objective to analyze the organization dimension of the VRIO model in a hotel in the city of Mossoró / RN. Semi-structured interviews were carried out with nine employees from different hierarchical levels, and it was possible to perceive the visions about the resources of the company. This research followed a qualitative approach with descriptive character and was carried out through a case study in a company of the hotel sector of the city of Mossoró / RN. The data analysis was performed through content analysis with the technological support of the ATLAS.ti software. The results indicated that the company has resources considered valuable, rare and difficult to imitate such know-how, the brand and the international standard. The organization of these resources is based on actions focused on supervision, differentiated management of people and planning.

Keywords: Resources; Competitive advantage; VRIO Model; Organization of resources.

\section{INTRODUÇÃo}

O mercado está cada vez mais competitivo e o consumidor tem se mostrado mais exigente e seletivo. Diante desse cenário, as empresas passaram a implementar estratégias que atendam ao mercado consumidor, ao mesmo tempo em que se tornam diferenciadas em relação à concorrência. Assim, refletir sobre estratégias organizacionais colabora para perceber fatores relevantes nos objetivos da maioria das empresas, como o crescimento e a lucratividade (VALLANDRO; TREZ, 2013). 
Além do lucro, as empresas estão se esforçando mais para adquirirem vantagem competitiva e esse fato tem motivado o crescente desenvolvimento de estudos nessa área. A questão da vantagem competitiva começou a ser abordada por diversas correntes de pesquisa da área da economia na década de 1970, quando se desenvolveram diferentes conceitos (VASCONCELOS; CYRINO, 2000). Esses estudos possibilitaram identificar características que definem quando uma empresa possui vantagem competitiva. Para Barney (1991), um empreendimento possui vantagem competitiva quando gera valor por meio de estratégias que seus concorrentes não são capazes de implementar.

Administrar e pensar estrategicamente as ações de uma empresa requer um planejamento elaborado com o fim de alcançar os objetivos organizacionais. Existe uma diversidade de elementos que constituem uma estratégia capaz de gerar vantagem competitiva, para isso a empresa deve tomar decisões com base nas estratégias que irá adotar, sendo essencial haver pensamento e planejamento estratégico (MORESCO; MARCHIORI; GOUVEA, 2014). O planejamento estratégico deve contemplar a maior diversidade dos recursos disponíveis numa organização, pois se constitui numa legítima fonte de vantagem competitiva e a forma como esses recursos são utilizados faz com que a competitividade seja alcançada no mercado (PAVÃO; SEHNEM; HOFFMANN, 2011).

A implementação de estratégias que atenderão aos objetivos organizacionais requer a análise interna da organização acerca dos recursos disponíveis. Dessa forma o ambiente interno constitui o cenário principal para o desenvolvimento de uma perspectiva que analisa os recursos competitivos empresariais para compreender como geram lucratividade e vantagem competitiva (KRETZER; MENEZES, 2006).

Nessa perspectiva se desenvolveu na década de 1990 a Resource Based View (RBV) ou Visão Baseada em Recursos (VBR), uma abordagem teórica que possui a premissa que é possível uma empresa obter desempenho superior mediante a capacidade de explorar seus recursos, tornando-os raros, valiosos e de difícil imitação (SALAZAR; MORAES; LEITE, 2015). A Visão Baseada em Recursos pode ser considerada uma teoria que explica o comportamento estratégico 
de uma empresa, com base na ideia de seleção, obtenção e disposição de recursos que podem gerar diferenciação e vantagem competitiva (CRUBELLATE; PASCUCCI; GRAVE, 2008).

No modelo VBR, os recursos de uma empresa podem ser utilizados para criar e implementar estratégias, estes recursos estão classificados em tangíveis e intangíveis (BARNEY; HESTERLY, 2007). Para explicar a relação entre os recursos da firma e a vantagem competitiva, em 1991, Jay Barney publicou um artigo no qual indicou os recursos e potencialidades de uma empresa como capazes de gerar vantagem competitiva. A análise se baseia em quatro indicadores, quais sejam: V (valor); R (raridade); I (imitabilidade imperfeita); e I (insubstituibilidade) (BARNEY, 1991; GONÇALVES; COELHO; SOUZA, 2011). Em 2002, Barney substituiu o I pelo O (organização), tornando-se o modelo VRIO (BARNEY, 2002).

O modelo VRIO (Valor, Raridade, Imitabilidade e Organização) é uma ferramenta importante para a análise dos recursos e capacidades de uma empresa na geração de vantagem competitiva (BARNEY; HESTERLY, 2007), no entanto é necessário que a empresa identifique os recursos que podem trazer a diferenciação e o alcance dos objetivos organizacionais. A questão da organização no modelo VRIO tem relação a como a empresa está se organizando para aproveitar ao máximo o potencial que seus recursos possuem em gerar a vantagem competitiva.

Sendo assim, surgiu o interesse de investigar a questão do elemento organização do modelo VRIO, em um hotel da cidade de Mossoró. A escolha pela pesquisa no setor hoteleiro se deu pelo interesse em investigar como um hotel internacional se mantém competitivo numa cidade de interior que não é turística. $O$ setor hoteleiro possui diferentes características que podem ser importantes para a gestão estratégica dos seus serviços (OKUMUS; ROPER, 1999), por este motivo é importante conhecer as ações estratégicas utilizadas nesse segmento para alcançar a vantagem competitiva. A indústria hoteleira possui significante força econômica, mas para se manter sustentável é necessário desenvolver competências essenciais para alcançar vantagem competitiva no domínio de negócios, combinando recursos e capacidades a fim de alcançar seus objetivos (OLSEN; TSE; WEST, 1998). Desse modo, o objetivo desse estudo é analisar a dimensão organização do Modelo VRIO na empresa investigada. 


\section{REFERENCIAL TEÓRICO}

Aborda-se os aspectos teóricos que embasam a pesquisa, apresentando discussões acerca da Visão Baseada em Recursos (VBR/RBV) e modelo VRIO, destacando o papel do elemento "organização".

\subsection{Visão baseada em recursos}

A transição da economia industrial para uma nova ordem econômica mundial provocou algumas mudanças na natureza da competição, fazendo surgir novas teorias e modelos relacionados à administração estratégica (OLIVEIRA; GONÇALVES; PAULA, 2013). As organizações possuem diferentes objetivos e para a sua concretização, planejam e implementam estratégias que atendam a esses objetivos. A estratégia pode ser explicada como uma teoria da firma que orienta como competir com sucesso (BARNEY, 2002). Porter (1999) complementa que a estratégia competitiva tem como base a diferenciação, a qual a empresa desenvolve um mix único de valores por meio de atividades diferenciadas e exclusivas.

Para se manter competitiva a organização deve investir em estratégias inovadoras, que estejam além do que está sendo realizado pelos seus concorrentes. Não é suficiente monitorar a concorrência ou imitar as suas estratégias, é necessário inovar e estar sempre sensível às mudanças que ocorrem no mercado hoteleiro (JÕ̃O et al., 2011). Segundo Olsen e Roper (1998), a competitividade e vantagem competitiva do setor hoteleiro dependem do método competitivo escolhido, seja por meio do enfoque nas competências e capacidades essenciais ou performance da firma.

A competição entre as empresas do setor hoteleiro não depende somente de como atua a concorrência, mas também de forças competitivas. As forças competitivas influenciam o posicionamento estratégico de uma empresa e esta deve identificar a origem das forças para se favorecer utilizando as estratégias genéricas definidas por Porter nos anos de 1980: liderança no custo total, diferenciação e enfoque (JOÃO et al., 2011). Nas empresas que oferecem o serviço de hotelaria é possível perceber que as estratégias de posicionamento competitivo estão relacionadas às estratégias genéricas de liderança no custo, diferenciação e enfoque, que representam meios de se alcançar um bom posicionamento (PORTER, 1999). Dentre essas estratégias, a 
diferenciação torna possível mensurar o grau de satisfação do cliente por meio da qualidade dos serviços oferecidos (ALVES, 2011).

Nas últimas décadas o campo da estratégia tem recebido diversas contribuições por meio de novas abordagens, perspectivas, teorias e modelos. Nesse contexto surge uma abordagem baseada em recursos que relaciona a formulação de estratégias aos recursos, capacidades, vantagem competitiva e lucratividade (VALLANDRO; TREZ, 2013). A visão baseada em recursos (VBR), originalmente denominada Resource Based View (RBV), começou a se fundamentar nos anos de 1950 com os estudos da economista Edith Penrose (RIBEIRO et al., 2012) que percebeu a importância de se ter recursos e capacidades significativos para manter o crescimento, obter fortalecimento e enfrentar as forças externas (LEITE; PRIMO, 2014).

A partir da década de 1980, as pesquisas de Penrose passaram a receber diversas contribuições para o desenvolvimento da VBR e estão fundamentadas nos estudos sobre "[...] a combinação entre a abordagem baseada em recursos, a do aprendizado organizacional, a das capacidades dinâmicas, a das capacidades organizacionais e a economia da tecnologia" (PAVÃO; SEHNEM; HOFFMANN, 2011, p. 230). Esses são aspectos destacados pelos autores clássicos da RBV, que unidos consolidam a ideia central dessa perspectiva.

A VBR reconhece os recursos da firma como elementos fundamentais para as estratégias, considerando que as competências, capacidades e habilidades possibilitam o conhecimento produtivo e organizacional. Essa abordagem revela uma análise detalhada das condições que favorecem a obtenção de retornos acima da média por meio dos recursos (KRETZER; MENEZES, 2006).

São diversos os recursos que podem gerar benefícios para uma empresa e Barney (1991) classifica os recursos da firma em três categorias amplas: recursos de capital físico, recursos de capital humano e recursos de capital organizacional. Posteriormente, Barney e Hesterly (2007) classificam os recursos do modelo VBR em tangíveis e intangíveis.

Diferentes termos são utilizados para descrever atributos estrategicamente relevantes. As terminologias mais utilizadas são: recursos, capacidades e competências, que na prática há pouca diferenciação no sentido que cada uma representa. Recursos são 
todos os atributos financeiros, físicos, individuais e organizacionais da empresa. As capacidades dizem respeito aos atributos internos da empresa que permitem a coordenação e exploração dos outros recursos. As competências auxiliam os gestores na concepção e implementação de estratégias de diversificação organizacional (BARNEY, 2002).

A perspectiva da VBR não está direcionada apenas em definir quais recursos são valiosos, mas implica também em compreender os motivos que levam uma organização a ter desempenho superior no ambiente competitivo. Além de ter um posicionamento de destaque no ambiente competitivo, a organização deve buscar atender às demandas do mercado por meio de recursos apropriados (CAMARGO; ZILBER, 2013).

Ter recursos valiosos não é suficiente para obter vantagem competitiva, é necessário possuir habilidade para gerenciar suas competências de modo a se adequar às mudanças ambientais. A empresa deve desenvolver capacidades de gerenciamento combinadas a outras habilidades organizacionais, ou seja, capacidades dinâmicas. As capacidades de uma empresa também são consideradas um recurso, que não é adquirido, mas se desenvolve aos poucos em sua rotina (TEECE; PISANO; SHUEN, 1997).

As competências essenciais são recursos organizacionais que servem de base para a competitividade, pois quando há competência para compartilhar e integrar vários recursos, a empresa tende a tornar-se competitiva (VALLANDRO; TREZ, 2013). Nessa visão não são todas as competências consideradas essenciais. Porém é possível identificar as competências essenciais através de três questionamentos: a competência é considerada uma significante fonte de diferenciação? Ela vai além de um único negócio? É difícil de ser imitada pelos concorrentes? (PRAHALAD, 1993).

A sustentação da vantagem competitiva com base na VBR também foi discutida por meio de um modelo teórico desenvolvido por Peteraf (1993), no qual aponta quatro elementos capazes de manter a competitividade de uma empresa: heterogeneidade, mobilidade imperfeita, limite de concorrência Ex ante e Limite de concorrência Ex post. Nesse modelo teórico, a heterogeneidade pressupõe que os recursos e capacidades da empresa são heterogêneos, obtendo retor- 
nos acima da média, aquelas empresas que têm recursos valiosos. Os recursos são imperfeitamente móveis quando não são úteis para outras empresas, pois são especializados para atender às necessidades específicas da empresa que os detém. Limite Ex ante ocorre quando antes mesmo de surgirem concorrentes a empresa já é possuidora de recursos valiosos, dificultando os possíveis concorrentes a competirem de igual para igual. O Limite Ex post é a capacidade de manter a vantagem competitiva sustentável ao longo dos anos, permanecendo estável diante da concorrência (PETERAF, 1993).

Barney (1991) e Peteraf (1993) compartilham ideias semelhantes sobre a relação entre os recursos e a vantagem competitiva. Na visão desses autores a heterogeneidade e a imobilidade de recursos são condições fundamentais para se obter vantagem competitiva, além disso concordam com a ideia de que os recursos da empresa devem ser únicos e de difícil imitação. Dessa forma, enquanto não houver a duplicação de benefícios para a concorrência por meio de estratégias adotadas, a vantagem competitiva permanecerá sustentável (BUZZERIO; MARCONDES, 2014).

É importante ressaltar que há diferenciação tratando-se de "vantagem competitiva" e "vantagem competitiva sustentável", Para Barney (1991) a vantagem competitiva ocorre quando uma empresa desenvolve uma estratégia que não está sendo utilizada por outro concorrente. Já a vantagem competitiva sustentável diz respeito à empresa que além de possuir uma estratégia não utilizada por outros, essa estratégia também é de difícil imitação.

Os estudos no campo da VBR propiciam reflexões importantes no que tange aos recursos de uma organização. Diante da competitividade, esses recursos podem representar uma legítima fonte de vantagem competitiva sustentável e geração de valor para a organização.

\subsection{Modelo VRIO}

A VBR destaca os recursos de uma empresa como um dos principais elementos geradores de vantagem competitiva, porém esses elementos devem ter atributos e qualificações, para ser capaz de gerar vantagem competitiva (SALAZAR; MORAES; LEITE, 2015). Nesse sentido, Barney (2002) afirma que os recursos e capacidades, assim como a heterogeneidade e imobilidade de recursos, não são suficientes 
para analisar as forças e fraquezas de uma organização. Para isso é necessário uma estrutura que incorpore essas definições e premissas.

A estrutura é um modelo de análise aplicado à Visão Baseada em Recursos que ficou amplamente conhecida como VRIO e que indica a utilidade dos recursos para a geração de vantagem competitiva (KNOTT, 2009). O modelo VRIO considera que os recursos são transformados em vantagem competitiva por meio da organização interna da empresa que conduz os recursos a serem valiosos, raros, inimitáveis e organizados (CARDEAL; ANTÓNIO, 2012).

Anteriormente, Barney (1991) apresentou indicadores para determinar se os recursos de uma empresa eram capazes de gerar vantagem competitiva sustentável. Nessa fase, foi concebido o modelo VRIS composto pelos elementos valor, raridade, imitabilidade imperfeita e substituibilidade (GONÇALVES; COELHO; SOUZA, 2011). De acordo com Gonçalves, Coelho e Souza (2011), na década seguinte Barney fez uma modificação substituindo o elemento "S" de substituibilidade pelo elemento "O" de organização. Segundo Barney (1991), a substituibilidade diz respeito aos recursos que podem ser substituíveis ou quando a concorrência possui recursos equivalentes.

O VRIO se estrutura em quatro questões: a questão do valor, da raridade, da imitabilidade e da organização. Essas questões ajudam a empresa a identificar se seus recursos e capacidades são uma força ou uma fraqueza (BARNEY, 2002). Portanto a vantagem competitiva de uma organização pode ser mantida se seus recursos atenderem aos quesitos do modelo VRIO: valor, raridade, imitabilidade e organização (CAMARGO; ZILBER, 2013).

O potencial competitivo dos recursos de uma empresa é determinado com base nos elementos que compõem o modelo VRIO. O valor de um recurso é percebido quando este permite que a empresa identifique oportunidades e neutralize ameaças. A raridade é percebida quando uma quantidade reduzida de empresas detém este recurso. A imitabilidade de um recurso é imperfeita quando outras empresas têm dificuldade para obter ou desenvolver o recurso. A organização dos recursos é o elemento que permite a empresa ajustar suas políticas e ações para explorar os recursos valiosos, raros e difíceis de imitar (BARNEY, 2002). 
As mudanças ambientais podem resultar na deterioração do valor e raridade de um recurso, ou seja, um recurso que agora é considerado valioso e raro pode não ser no futuro. Quando um recurso perde o valor ou deixa de ser raro, a organização pode reinventá-lo para que atenda às mudanças do ambiente, sendo possível também aplicar outras estratégias para este mesmo recurso (LEMOS; TORTATO, 2009; SANEMATSU; SILVA; VIEIRA, 2016).

É importante desenvolver e aplicar estratégias que permitam os recursos da organização permanecerem valiosos, raros, inimitáveis e organizados. Uma vez que os recursos se tornam desvalorizados, obsoletos e fáceis de imitar, pois geralmente tendem a diminuir ou desaparecer (GRANT, 1991).

\subsection{Organização: elemento essencial do modelo VRIO}

Cada organização tem sua maneira própria de organizar seus recursos, suas próprias estratégias de mercado que estão voltadas para a configuração tecnológica, estrutural e processual (VALLANDRO; TREZ, 2013). Os fatores externos e internos exercem forte influencia na organização dos recursos e na tomada de decisões de como disponibilizar e alocar esses recursos (CRUBELLATE; PASCUCCI; GRAVE, 2008).

As empresas que conseguem desenvolver formas de integrar os recursos, podem obter mais vantagem competitiva. $\mathrm{O}$ " $\mathrm{O}$ ” do modelo VRIO representa a capacidade da organização em organizar os recursos que são valiosos, raros e difíceis de imitar (CARDEAL; ANTÓNIO, 2012). Em complemento a definição do papel desse elemento, Gonçalves, Coelho e Souza (2011) afirmam que o ponto central da questão da organização está em como a empresa administra o valor, raridade e imitabilidade de seus recursos.

A organização deve estar voltada para os recursos adequados. O elemento "O" do modelo VRIO viabiliza a empresa para tirar o máximo de proveito dos seus recursos que são valiosos, raros e inimitáveis. Porém quando a empresa se organiza para explorar recursos que não possuem esses atributos, seus custos aumentam, os lucros diminuem e o potencial competitivo é reduzido, pois está se dedicando a recursos considerados fracos (PAVÃO; SEHNEM; HOFFMANN, 2011). Portanto, para conseguir vantagem devem ser 
consideradas as questões direcionadas à seleção e utilização dos recursos (CRUBELLATE; PASCUCCI; GRAVE, 2008).

No processo de organização a empresa deve estabelecer seus recursos e capacidades complementares que juntos aos outros recursos geram a capacidade de explorar oportunidades e neutralizar ameaças do ambiente. Assim, essa capacidade que a empresa tem em organizar seus recursos é uma fonte de vantagem competitiva sustentável (LEMOS; TORTATO, 2009).

Barney (2002) afirma que na questão da organização é indispensável o auxílio de alguns componentes que muitas vezes são denominados "recursos e capacidades complementares", por não terem a capacidade de gerar vantagem competitiva sozinhos e por isso complementam outros recursos e capacidades. Barney e Hesterly (2007) identificam esses componentes representados pela estrutura formal de reporte, sistemas de controle gerencial formais e informais e políticas de remuneração. Estes aliados a outros recursos e capacidades propiciam o aproveitamento do potencial de vantagem competitiva numa empresa.

O VRIO deve ser desenvolvido como uma ferramenta prática e para isso é necessário considerar os impactos das condições internas e externas, visto que estes influenciam os recursos sustentáveis. Dessa forma a organização dos recursos e capacidades depende de como ocorre a gestão dessas condições (KNOTT, 2009).

O elemento organização é representado pela capacidade e esta se desenvolve nos processos organizacionais. Uma empresa que desenvolve melhores formas de organizar seus recursos está mais suscetível a obter fontes de vantagem competitiva mais fortes (CARDEAL; ANTÓNIO, 2012).

O atributo "Organização" do modelo VRIO é o mais diferenciado dessa teoria, pois possui uma intangibilidade mais consistente, dificultando assim a imitação. O atributo "Organização" deve estar em conjunto com os outros elementos do modelo VRIO, pois sozinho não é capaz de gerar vantagem competitiva (GONÇALVES; COELHO; SOUZA, 2011).

A incorporação do elemento "O" ao novo modelo VRIO revela a diferenciação e a relevância para a gestão estratégica que este atributo possui, pois se os recursos e capacidades valiosos, raros e 
de difícil imitação não estiverem organizados, é inviável a geração de vantagem competitiva sustentável.

A organização dos recursos pode levar uma empresa a ter desempenho superior em relação aos seus rivais e para isso as estratégias e a eficácia operacional são essenciais. A eficácia operacional consiste no ato da empresa desempenhar melhor que seus concorrentes determinadas atividades, além de ser capaz de aproveitar melhor os insumos, diminuir custos e atingir altos níveis de diferenciação (PORTER, 1999).

Todos os recursos de uma empresa são importantes, porém existem aqueles que se administrados de forma adequada, facilitam o alcance de objetivos organizacionais. A administração dos recursos está diretamente ligada à organização destes, que de acordo com a Figura 2, essa organização possibilita explorar, estabelecer e integrar recursos e capacidades para a construção de uma vantagem competitiva sustentável. Desse modo, é possível afirmar que o elemento "O" do modelo VRIO é a fundamental para todos os recursos competitivos de uma empresa. A existência de recursos competitivos não é suficiente quando não se desenvolve a capacidade de organizá-los.

\subsection{A visão baseada em recursos no setor hoteleiro}

Assim como nos demais setores da economia, o de hotelaria busca se manter competitivo por meio de estratégias que possibilitem atrair clientes e superar seus concorrentes. Há poucas pesquisas sobre a RBV com ênfase em hotelaria (SANTOS et al., 2015), porém os estudos já desenvolvidos apontam que os recursos são verdadeiramente fonte de vantagem competitiva e a forma como as empresas hoteleiras gerem esses recursos tem se tornado uma ação valiosa diante da competitividade.

Segundo Santos, Gohr e Cruz (2011), empresas do setor hoteleiro buscam constantemente formas de se diferenciar da concorrência, para isso devem manter a competitividade com a criação de valor, desenvolvendo competências e recursos de maneira diferente de seus concorrentes. Nesse contexto é importante fazer a identificação dos recursos estratégicos e a exploração de maneira diferenciada.

A formulação das estratégias de uma empresa com base na RBV tem início a partir da identificação dos recursos estratégicos, 
classificando-os de acordo com sua especificidade nas categorias de recursos financeiros, físicos, humanos e organizacionais. Dessa maneira, uma empresa do setor hoteleiro pode obter vantagem competitiva mediante desempenho superior que seja resultado de ações estratégicas que utilizam de maneira eficiente seus recursos (SILVA; TEIXEIRA, 2010).

De acordo com pesquisa realizada por Hayashi Jr., Abib e Bouscheid (2014), 90\% dos hotéis são micro e pequenas empresas, que apesar de possuírem menor porte também organizam seus recursos e capacidades para colocar em prática suas estratégias. O sucesso das estratégias adotadas por essas empresas dependem em parte das competências desenvolvidas para gerir os recursos (SANTOS; GOHR; CRUZ, 2011).

A VBR trata da heterogeneidade dos recursos como forma de alcançar resultados, sendo por meio do uso, composição, interação e renovação de recursos. Quando aliada a outras perspectivas teóricas, a VBR possibilita um melhor entendimento de como as empresas do setor de hotelaria utilizam seus recursos para se manterem competitivas (HAYASHI; ABIB; BOUSCHEID (2014).

A utilização de recursos está diretamente associada à gestão de custos no setor hoteleiro, que consequentemente beneficia a empresa com a liderança em custos. Assim é importante ressaltar que a gestão de custos não significa controlar e reduzir indiscriminadamente os custos de uma empresa, mas sim otimizar os recursos disponíveis para se oferecer serviços e produtos de qualidade com mínimo de desperdício (POMPERMAYER, 2017). Barney e Hesterly (2007) discutem a liderança em custos como uma estratégia que visa ganhar vantagem sobre a concorrência por meio da redução de custos, mantendo seus custos baixos para atender seu público alvo sem deixar de lado as outras estratégias organizacionais. Os autores afirmam ainda que a vantagem da liderança em custos é possível de ser obtida até mesmo quando empresas oferecem os mesmos produtos, ou seja, é uma vantagem possível de se obter no setor hoteleiro.

Uma nova visão pode ser apresentada pela Visão Baseada em Recurso por meio do desenvolvimento do valor, da sustentabilidade e da versatilidade dos recursos de uma empresa hoteleira, fazendo uma relação entre as estratégias e recursos. Na RBV é importante 
identificar estratégias e fazer a avaliação dos recursos disponíveis, pois dessa forma percebe-se que os recursos são os principais responsáveis pela viabilização das estratégias (SANTOS et al., 2015).

No setor hoteleiro em relação à gestão dos recursos também se faz necessário desenvolver competências essenciais que se definem em processos, habilidades e ativos nos quais a empresa se baseia para alcançar a vantagem competitiva (OLSEN; TSE; WEST, 1998).

Ainda sobre as competências essenciais nas empresas de hotelaria, Olsen, Tse e West (1998) desenvolveram um modelo estrutural que explica o desenvolvimento de tais competências. Refere-se principalmente à relação entre cliente e funcionários que acontece a troca de processos, ou seja, os produtos e serviços que são oferecidos pelo hotel. Para alcançar o sucesso dessa troca ou relação com o cliente, é necessário o desenvolvimento das competências essenciais, assim como as competências periféricas que servem de apoio e sustentação das competências essenciais.

A sustentação das competências essenciais depende em parte das capacidades dinâmicas desenvolvidas pela empresa, pois o ambiente sofre modificações constantemente e com isso deve desenvolver a capacidade de se adequar para continuar competitiva. Há uma combinação de competências e recursos e a capacidade dinâmica possibilita a empresa fazer adequações em suas competências para seguir as exigências do ambiente interno e externo (MARTINS et al., 2013)

Nesta revisão bibliográfica, observa-se que o modelo VRIO na hotelaria ainda é um tema pouco explorado. Mas, ressalta-se a importância da análise com base no modelo VRIO no setor hoteleiro, pois com a identificação dos recursos valiosos, raros, difíceis de se imitar e organizados, é possível formular estratégias consistentes para a geração de vantagem competitiva. Além disso, o modelo VRIO possibilita a identificação de recursos e capacidades que precisam ser desenvolvidos por empresas hoteleiras (SALGADO; COLOMBO, 2015). Dessa forma, esta pesquisa busca cobrir essa lacuna e colaborar no desenvolvimento de uma literatura mais robusta para empresas desse setor econômico. 


\section{Metodologia}

Uma pesquisa se constitui de um processo sistemático que procura apontar respostas para uma problemática, dessa maneira para que seja desenvolvida é necessário escolher cuidadosamente os métodos, processos e técnicas que serão utilizados (DIEHL; TATIM, 2004). Esta pesquisa seguiu uma abordagem qualitativa, na visão de Neves (2006), a pesquisa qualitativa tem como objetivo explorar e interpretar os fenômenos do mundo social (VIEIRA; RIVERA, 2012), para tanto se constitui em um conjunto de diferentes técnicas de interpretação que buscam descrever e decodificar significados complexos.

O objetivo principal desta pesquisa foi analisar como a empresa investigada organiza seus recursos com base no modelo VRIO, portanto, para atender o objetivo, esta pesquisa tem caráter descritivo, pois busca identificar, descrever e analisar a prática dessa empresa em relação a esse aspecto.

Para fins de procedimentos técnicos esta pesquisa se realizou por meio de estudo de caso de uma empresa do setor hoteleiro da cidade de Mossoró, onde se buscou explorar e compreender acontecimentos e ações estratégicas no contexto da empresa. O estudo de caso é um método de investigação que se caracteriza pela busca da compreensão da dinâmica presente em um ambiente e de acordo com o objetivo da pesquisa pode combinar métodos de coleta de dado como arquivos, entrevistas, questionários e observações (EISENHARDT, 1989).

$\mathrm{O}$ instrumento de coleta utilizado nesta pesquisa foi a entrevista semiestruturada que de acordo com Boni e Quaresma (2005) pode conter perguntas fechadas e abertas com base em um roteiro de questões previamente definidas e o entrevistador deve estar atento ao momento certo de direcionar as perguntas para o assunto o qual interessa obter informações mais precisas. As entrevistas foram realizadas no próprio hotel e em dois dias no turno vespertino, onde cada entrevista foi realizada de maneira individual. Foram selecionados para responderem à entrevista nove de vinte e três funcionários, dentre eles a gerente do hotel, uma trainee, uma supervisora de andares, três atendentes de hospedagem, duas atendentes de A e B e uma camareira. Assim a obtenção dos dados aconteceu por meio de informações externadas pelos entrevistados selecionados 
nos diferentes níveis estratégicos da empresa. Para responder o objetivo da pesquisa, o critério de seleção dos entrevistados utilizado, considerou os sujeitos dos diferentes níveis estratégicos, de forma não probabilística e intencional.

A análise de dados desta pesquisa se realizou por meio da análise de conteúdo com o suporte tecnológico do software ATLAS.ti, sendo este, essencial para a análise dos dados, pois por meio da inserção das entrevistas no software foi possível categorizar e codificar os dados, gerando ao final redes que auxiliaram na apresentação dos resultados. Os dados coletados por meio de entrevistas semiestruturadas foram analisados com base na análise de conteúdo discutida por Bardin (2011), que divide o método de análise em organização da análise, codificação, categorização e inferência. Estas etapas possibilitam a análise e interpretação das falas dos entrevistados no intuito de formular os resultados e conclusões da pesquisa.

\section{RESULTADOS}

A pesquisa foi realizada no Hotel Ibis que pertence ao grupo Accor Hotels, uma empresa que está presente em 92 países com mais de 3.700 hotéis dos mais luxuosos aos mais econômicos. O Ibis é uma das 20 marcas gerenciadas pelo grupo Accor e conta com mais de 1.000 hotéis em 61 países, sendo considerada a rede de hotéis líder no segmento econômico, na Europa e América Latina. A rede de hotéis Ibis se caracteriza principalmente por oferecer serviços de qualidade com tarifas acessíveis (ACCOR HOTELS, 2017).

A unidade Ibis onde se realizou a pesquisa está localizada na cidade de Mossoró/RN e está em funcionamento há quatro anos. O hotel fica localizado próximo ao centro da cidade e possui uma estrutura com 154 acomodações, restaurante e bar, estacionamento e internet sem fio grátis para os hóspedes. Possui um quadro com 23 funcionários distribuídos nas funções de gerente geral, trainee, supervisão de andares, administrativo, hospedagem, alimentos e bebidas, governança e manutenção.

Dos nove entrevistados, quatro estão trabalhando na unidade desde sua abertura em 2012. As entrevistas foram realizadas em dois dias e individualmente, para que fosse possível perceber a visão de cada um acerca do tema pesquisado. Todos se mostraram 
disponíveis a realizar a entrevista, fornecendo informações importantes para o estudo.

\subsection{RECURSOS COMPETITIVOS}

\subsubsection{Recursos valiosos, raros e difíceis de imitar}

A Visão baseada em recursos considera que a combinação entre estratégias e os recursos de uma empresa pode gerar vantagem competitiva sustentável (CRUBELLATE; PASCUCCI; GRAVE, 2008). A partir dos dados coletados percebeu-se que a empresa possui recursos competitivos que aliados às suas estratégias são capazes de gerar vantagem sobre os seus concorrentes.

Foram identificados recursos tangíveis e intangíveis (BARNEY; HESTERLY, 2007), nomeados anteriormente por Barney (1991) como recursos de capital físico, recursos de capital humano e recursos de capital organizacional. Dentre os recursos destacam-se três intangíveis que possuem as características de valor, raridade e imitabilidade simultaneamente. Essas características atendem ao que está definido no modelo VRIO, o recurso deve ser valioso, raro, de difícil imitação e organizado para gerar vantagem competitiva sustentável (CAMARGO; ZILBER, 2013). Os três recursos que possuem as três primeiras características do modelo são: know-how, marca e padrão internacional. A figura 1 mostra os recursos da empresa pesquisada que possuem valor, raridade e imitabilidade, além dos outros recursos que estão relacionados a eles.

De acordo com a análise dos dados constatou-se que dentre todos os recursos que a empresa possui, o know-how, a marca e o padrão internacional são valiosos, porque permitem a empresa aproveitar oportunidades de mercado, raros porque são específicos da empresa e difíceis de serem obtidos por outras empresas e de difícil imitação porque a concorrência dificilmente pode copiar. Barney (2002) afirma que essas características permitem a empresa identificar se seus recursos são uma força ou uma fraqueza, nesse caso, os recursos know-how, marca e padrão internacional representam uma força que possibilita a empresa ser competitiva no mercado hoteleiro. 
Figura 1 - Recursos competitivos valiosos, raros e difíceis de imitar

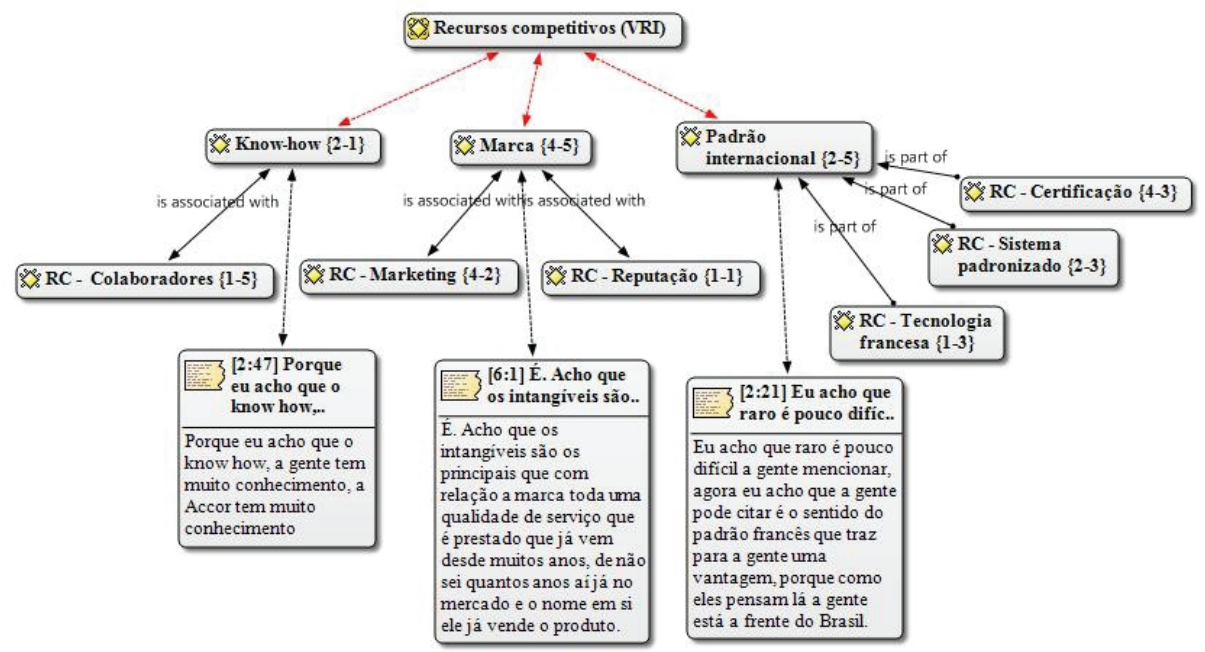

Fonte: Elaboração dos autores com o auxílio do ATLAS.ti (2017).

O know-how é um recurso classificado como intangível e importante na geração de vantagem competitiva (BARNEY; HESTERLY, 2007). De acordo com a Entrevistada 1, a empresa possui conhecimento adquirido por meio de capacitação constante em relação às normas, procedimentos e métodos. O know-how da empresa está diretamente relacionado aos colaboradores, pois o conhecimento é compartilhado com todos, independente de hierarquia.

O Ibis e a Accor são marcas já consolidadas no mercado, principalmente por terem conquistado a confiança do consumidor pela qualidade dos seus serviços. Assim, se construiu ao longo dos anos uma reputação positiva que de acordo com Barney e Hesterly (2007) faz parte dos recursos organizacionais que são construídos na coletividade, pelas pessoas que fazem parte da empresa. A reputação é essencial na fidelização dos hóspedes que utilizam os hotéis dessa marca, assim como na conquista de novos clientes. Outro aspecto relacionado à marca é o marketing que a empresa faz para mostrar suas qualidades. O marketing é realizado por meio de redes sociais, página virtual, programas de tv de grande audiência e diretamente com os hóspedes através dos colaboradores. 
O padrão internacional é um diferencial do Ibis, pois todos os procedimentos e normas seguem o padrão desenvolvido na França, país de origem da empresa. Todas as unidades devem seguir esse padrão em todos os aspectos, porém com pequenas adaptações à realidade local e isso permite a empresa deter recursos que os seus concorrentes não possuem, obtendo vantagem sobre eles.

O padrão internacional exige que as unidades Ibis sigam o modelo determinado e dentre essas exigências merecem destaque a certificação e o sistema padronizado que segue o padrão de tecnologia francesa. Por se tratar de uma empresa francesa, a Accor utiliza a estratégia de padronização em todas as suas unidades Ibis, incluindo procedimentos, estrutura, refeições e gestão de pessoas, tudo isso com o objetivo de oferecer sempre qualidade para os hóspedes. O sistema é integrado e padronizado, facilitando a organização dos procedimentos e possibilitando um melhor controle dos recursos organizacionais. Ainda em relação ao padrão internacional, é importante dar ênfase à certificação que confere à empresa mais um diferencial. A unidade Ibis Mossoró possui os certificados ISO 9.000 (ambiental) e ISO 14.000 (de processos), certificação difícil de encontrar em outras empresas locais do mesmo setor, assim como afirma a entrevistada 1: "[...] Único. Ah, tem a parte da certificação que é muito difícil [...] Ninguém tem certificação aqui em Mossoró."

Todos esses recursos se definem como intangíveis (BARNEY; HESTERLY, 2007), porém também se enquadram em duas das categorias definidas por Barney (1991): recursos de capital físico, porque envolve tecnologia e recursos de capital organizacional, porque estão relacionados à estrutura organizacional da empresa.

Os recursos do hotel Ibis Mossoró identificados como valiosos, raros e difíceis de imitar também se caracterizam pela heterogeneidade e imobilidade, que segundo Barney (1991) e Peteraf (1993), são condições essenciais para gerar vantagem competitiva. Além disso, esses recursos possibilitam o desenvolvimento de competências essenciais (PRAHALAD, 1993), pois aliam habilidades e tecnologias gerando benefícios para os clientes. 


\subsubsection{A equipe de colaboradores}

Apesar de ser um recurso comum em todas as empresas, os colaboradores podem influenciar na construção de uma marca forte e reputação, transmitindo ao cliente toda a qualidade nos serviços oferecidos pela empresa. Os colaboradores não se caracterizam ao mesmo tempo como um recurso valioso, raro e difícil de imitar, porém representam um recurso competitivo capaz de proporcionar vantagem diante da concorrência (ver figura 2).

\section{Figura 2 - Colaboradores}

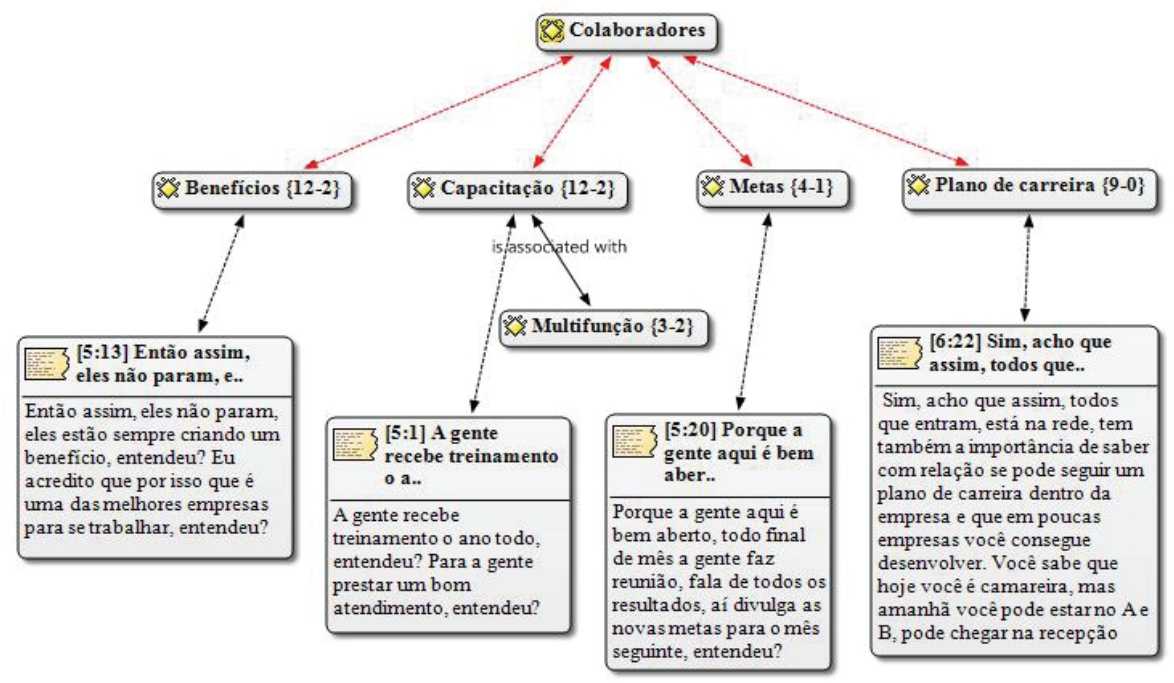

Fonte: Elaboração dos autores com o auxílio do ATLAS.ti (2017).

O Hotel Ibis Mossoró conta com uma equipe reduzida de colaboradores e investe em benefícios e treinamentos para que os objetivos organizacionais sejam alcançados. De acordo com Barney e Hesterly (2007), os colaboradores de uma empresa representam os recursos humanos, incluindo inteligência, experiência e treinamento dos funcionários. A equipe de colaboradores do Ibis Mossoró é um recurso também importante para que a empresa obtenha vantagem competitiva e por esse motivo está sempre desenvolvendo ações voltadas para a área de recursos humanos.

A empresa oferece aos funcionários diferentes benefícios como refeições, sala de descanso, plano de saúde e odontológico, compu- 
tador com internet, bonificações por atingirem as metas, boas condições de trabalho e oportunidade de atuar em outras funções. Dessa forma a empresa oferece possibilidades de crescimento profissional por meio do plano de carreira que o colaborador pode construir uma carreira passando pelas diferentes funções até chegar aos cargos mais altos hierarquicamente. Toda essa valorização do colaborador traz motivação para a equipe e isso reflete no desempenho das funções, que também é percebido pelos hóspedes.

Através das falas dos entrevistados percebeu-se que o clima organizacional da empresa é positivo e facilita o atingimento das metas, pois os colaboradores sentem-se motivados a se dedicarem em suas funções de maneira satisfatória. As metas são discutidas nas reuniões mensais, onde é feita uma avaliação do que já se atingiu e o que pode ser melhorado.

A capacitação é um dos fatores que tornam os colaboradores um recurso valioso para a empresa, pois através de cursos, treinamentos e reciclagens, os funcionários absorvem os valores organizacionais e desenvolvem capacidades. De acordo com Barney (2002) essas capacidades são atributos internos da empresa e facilitam a exploração e organização dos recursos.

Todas as ações desenvolvidas pela empresa são apoiadas em treinamentos dos seus colaboradores, que são capacitados para desempenhar a multifunção, ou seja, todos estão aptos a realizar atividades de todos os setores, facilitando a integração das atividades e união das equipes. A empresa investe bastante na capacitação dos seus funcionários, pois acredita que isso reflete de maneira positiva na visão do cliente.

A constante capacitação pela qual passam os colaboradores do Hotel Ibis faz com que a organização esteja preparada para possíveis mudanças de mercado, pois são desenvolvidas capacidades dinâmicas que de acordo com Teece, Pisano e Shuen (1997), são criadas a partir da rotina da empresa e geram habilidades de gerenciamento de competências que permitem se adequar às mudanças ambientais.

Os recursos competitivos identificados no Hotel Ibis Mossoró não seriam capazes de gerar vantagem competitiva se não estivessem organizados de maneira adequada para isso. Dessa forma verificou-se que a empresa utiliza estratégias que permitem organizar e aproveitar da melhor maneira seus recursos. 


\subsection{Organização dos recursos competitivos}

Ao desenvolver capacidades e competências essenciais, o Hotel Ibis se torna uma empresa competitiva, pois também se mostra capaz de integrar e organizar seus recursos, assim a organização adquire elevados níveis de competitividade (VALLANDRO; TREZ, 2013). As estratégias utilizadas pelo Ibis Mossoró permitem a empresa manter a organização em diversos aspectos. De acordo com a análise das informações pode-se constatar que a empresa organiza os recursos valiosos, raros e difíceis de imitar por meio da fiscalização, gestão diferenciada de pessoas e planejamento (ver figura 3).

É importante destacar que os elementos associados à organização dos recursos estão também relacionados ao padrão exigido para todas as unidades do Hotel Ibis, ou seja, o padrão adotado pela empresa viabiliza a integração e organização dos recursos competitivos.

A fiscalização em seus diferentes aspectos é uma maneira da empresa manter seus recursos organizados e isso ocorre por meio de auditorias realizadas pela sede a cada três meses, seis meses ou um ano, de acordo com a necessidade de cada setor.

As auditorias têm o objetivo de verificar se as normas e procedimentos exigidos pelo padrão estão sendo respeitados, assim os valores defendidos pela marca podem ser preservados, mantendo sua boa reputação. Para isso é necessário manter a certificação de qualidade, além de controlar os produtos e serviços oferecidos aos hóspedes.

No aspecto gestão diferenciada de pessoas, o Ibis Mossoró direciona estratégias específicas para a gestão de recursos humanos. O treinamento multifuncional que os colaboradores recebem permite que se tenha conhecimento dos procedimentos específicos de todas as funções. As reuniões mensais também são uma forma de organizar os recursos, pois são momentos oportunos para avaliar as estratégias, verificar se os recursos estão sendo bem aproveitados e apontar melhorias no que for necessário. Com base na Visão Baseada em Recursos é possível afirmar que o treinamento de funcionários e as reuniões possibilitam fazer a relação entre estratégias e recursos, concordando com Santos et al. (2015) que confirmam a importância da avaliação dos recursos disponíveis para a viabilidade das estratégias. 


\section{Figura 3 - Organização dos recursos competitivos}

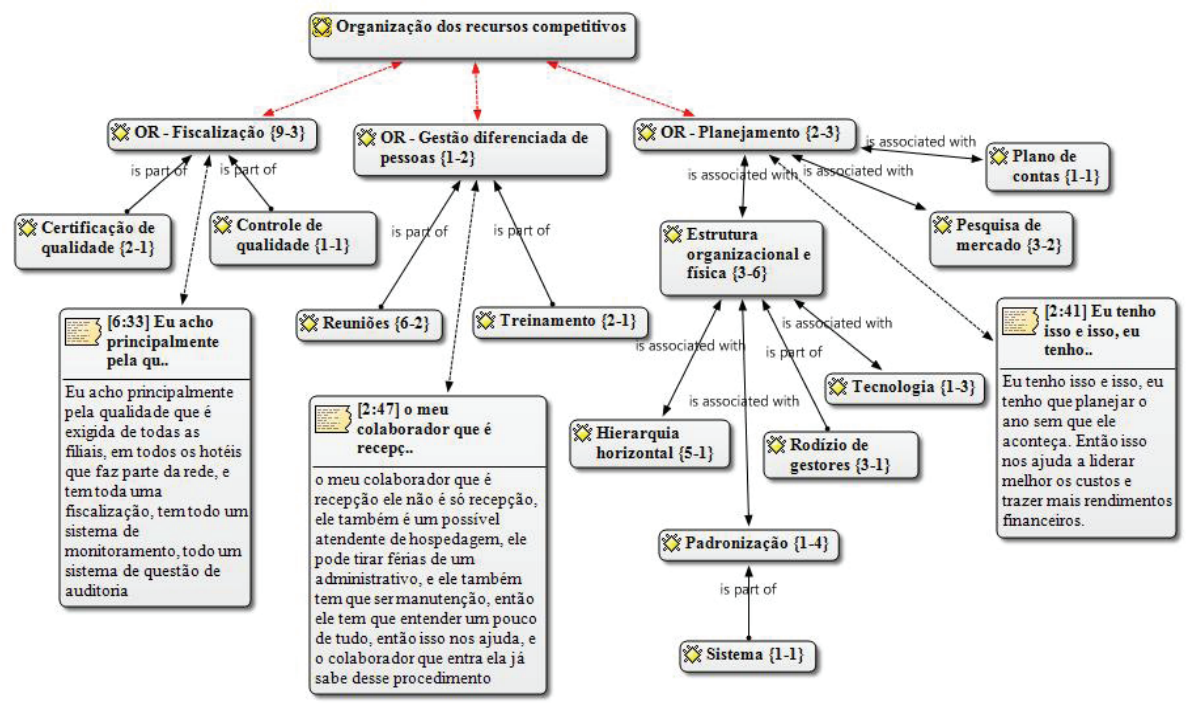

Fonte: Elaboração dos autores com o auxílio do ATLAS.ti (2017).

O planejamento também se constitui um processo essencial na organização dos recursos competitivos do Hotel Ibis Mossoró, pois permite analisar os recursos disponíveis e aproveitá-los da melhor maneira. O planejamento viabiliza a organização dos recursos aproveitando melhor aqueles que são valiosos, raros e difíceis de imitar, mas quando a empresa explora recursos que não possuem essas características está correndo o risco de perder potencial competitivo (PAVÃO; SEHNEM; HOFFMANN, 2011), por esse motivo, o planejamento deve se direcionar para a seleção e utilização dos recursos adequados (CRUBELLATE; PASCUCCI; GRAVE, 2008).

As estruturas organizacional e física do Ibis Mossoró tornam viável a organização dos recursos. A hierarquia é horizontal, todos são subordinados apenas à gerente geral que só fica no máximo dois anos em cada unidade, pois há o rodízio de gestores. Essa é uma estratégia utilizada pela empresa para a organização dos seus recursos humanos. Os recursos tecnológicos disponíveis auxiliam a empresa a manter-se sempre organizada e a tecnologia francesa é um diferencial em relação à concorrência. O sistema é todo padro- 
nizado sendo a base para toda a gestão hoteleira do Ibis, por isso é essencial que seja um sistema organizado e eficaz.

Faz parte do planejamento do Hotel Ibis, o plano de contas e a pesquisa de mercado que permitem a empresa avaliar seus resultados e definir suas estratégias. O plano de contas é o planejamento financeiro realizado anualmente de maneira antecipada, ou seja, o ano seguinte é planejado no ano atual. Da mesma forma é realizada constantemente pesquisas de mercado para conhecer melhor as estratégias dos concorrentes, aproveitando as oportunidades e neutralizando ameaças. O planejamento é uma capacidade interna que de acordo com Lemos e Tortato (2009) quando associada aos outros recursos da empresa podem gerar a capacidade de explorar oportunidades e neutralizar ameaças do ambiente, tornando possível obter vantagem competitiva.

A fiscalização, gestão diferenciada de pessoas e planejamento se constituem capacidades que Barney (2002) definiu como complementares, pelo fato de não serem capazes de gerar vantagem competitiva sozinhas. Assim, essas capacidades complementam outros recursos e capacidades que a empresa possui e juntos beneficiam a empresa com a vantagem competitiva sustentável.

Mesmo possuindo uma estrutura que possibilita a organização de seus recursos, o Hotel Ibis Mossoró também demonstrou ter falhas em relação a esse elemento do modelo VRIO. A gestão é centralizada, portanto a gerência está sempre ligada aos procedimentos deixando as estratégias em segundo plano. Desse modo, em alguns casos não é possível desenvolver estratégias que possibilitem a organização dos recursos.

Por meio da organização dos recursos, o Hotel Ibis Mossoró consegue diminuir seus custos e passar essa redução no valor final para os clientes. O Hotel é administrado pelo Grupo Accor que possui em seu portfólio hotéis com diferentes padrões para atender aos variados tipos de público. O Ibis Mossoró faz parte da linha econômica do grupo Accor. Uma das suas principais características é oferecer estadia de qualidade por um valor acessível e isso é possível porque a empresa utiliza a estratégia de liderança em custos.

O Ibis Mossoró tem como um dos seus principais atrativos as tarifas econômicas, considerando o padrão de qualidade que é oferecido 
aos hóspedes. Mas como oferecer qualidade aos clientes mantendo tarifas promocionais em grande parte do ano? De acordo com as informações analisadas, a liderança em custos é fruto da eficácia operacional, planejamento financeiro e quadro de funcionários reduzido.

A liderança em custos é uma das estratégias genéricas definidas por Porter (1999), considerada como uma ação de posicionamento competitivo no setor hoteleiro. A liderança em custos do Ibis Mossoró ocorre devido à eficácia operacional, planejamento financeiro e número reduzido de colaboradores.

Possuir liderança em custos no setor hoteleiro significa ir além de redução de gastos, é ter a capacidade de oferecer serviços de qualidade aos hóspedes com o menor custo possível e mesmo oferecendo serviços similares aos de seus concorrentes, mostrar-se diferente. Essa é uma estratégia genérica que torna possível obter vantagem competitiva e assim como afirma Barney e Hesterly (2007), a empresa não deve abandonar suas outras estratégias, pois do contrário vai oferecer ao cliente um serviço ou produto de baixo custo e baixa qualidade.

Por meio de estratégias que permitem liderar custos e aproveitar melhor os recursos disponíveis, a empresa pesquisada promove a organização dos seus recursos competitivos que são valiosos, raros e difíceis de imitar. Para tanto, é possível afirmar que o padrão seguido por todas as unidades Ibis facilita essa organização, permitindo fazer controle sobre os recursos que permitem a empresa obter vantagem diante dos concorrentes locais.

\section{Considerações Finais}

O estudo foi realizado na unidade do Hotel Ibis em Mossoró que é administrada pela Accor Hotels, onde foram realizadas entrevistas semiestruturadas com nove colaboradores de diferentes níveis hierárquicos. Com os dados obtidos, foi possível identificar os principais recursos competitivos da empresa e dentre esses, três possuem as características de valor, raridade e imitabilidade, atendendo ao que determina o modelo VRIO em relação aos recursos que podem gerar vantagem competitiva.

O know-how, a marca e o padrão internacional são os recursos que a empresa possui e que são difíceis de serem obtidos ou copia- 
dos por seus concorrentes. As estratégias utilizadas pela empresa e que promovem a organização desses recursos estão fundamentadas na fiscalização, gestão diferenciada de pessoas e planejamento. $\mathrm{O}$ Ibis Mossoró possui certo rigor em relação às normas que devem ser seguidas para atender ao padrão estabelecido pela sede, por isso passa por diversas auditorias durante o ano. Além disso utiliza estratégias para gerir seus recursos humanos de forma a beneficiar os hóspedes com serviços de qualidade. Por fim, o planejamento é a base para a gestão e organização dos recursos, possibilitando o seu aproveitamento adequado.

Percebe-se que os colaboradores se revelam como um recurso muito importante para o Hotel Ibis, considerando que estão em contato direto com o consumidor dos serviços oferecidos pela empresa, os hóspedes. O atendimento e os serviços de maneira geral, oferecidos pelos colaboradores do Ibis são os motivadores das avaliações positivas por parte dos hóspedes e para que isso seja viável, há treinamentos constantes para que a qualidade permaneça na empresa.

Observa-se que a multifunção é um aspecto essencial para a capacitação dos recursos humanos, como também para a posição de liderança em custos obtida pela empresa. Os colaboradores desempenham diferentes funções e por isso são considerados aptos para realizar diferentes atividades sem afetar a qualidade dos serviços oferecidos. Assim, a empresa faz o enxugamento do seu quadro de funcionários, evitando o aumento dos custos com pessoal. Ainda sobre a liderança em custos, foi possível identificar que o planejamento financeiro é essencial para que se tenha uma visão real dos recursos disponíveis e dos limites de custos que refletem nos valores de tarifas oferecidas aos hóspedes.

Em relação à organização dos seus recursos, é importante salientar que o padrão seguido pela empresa possibilita o alcance de seus objetivos organizacionais, assim como manter os recursos competitivos organizados para gerar vantagem competitiva. Com isso é possível afirmar que o Hotel Ibis Mossoró desenvolve estratégias que resultam na organização de seus recursos valiosos, raros e difíceis de imitar.

Para o campo de estudo da administração, este trabalho contribui no enriquecimento teórico da administração estratégica no 
que tange à gestão de recursos de uma empresa. Esta pesquisa possibilita o avanço da compreensão de estratégias de identificação e organização de recursos no setor hoteleiro, revelando a importância da utilização das capacidades internas de uma empresa no aproveitamento eficaz de seus recursos.

Embora utilize algumas estratégias de organização dos recursos, percebe-se que a empresa por ter um padrão a seguir ocupa o tempo da gestora com procedimentos e com isso as estratégias não recebem a devida atenção. Portanto, sugere-se que as atividades centralizadas apenas na gerência sejam delegadas a outras pessoas capacitadas para isso, dessa forma haverá mais tempo para a gestora da unidade planejar e colocar em prática estratégias voltadas para a gestão de recursos.

Não houve limitações para o desenvolvimento da pesquisa, contudo, esse é um tema pouco explorado não somente no setor de hotelaria, mas também em outros setores da economia. Por isso a sugestão de estudo é para que haja maior aprofundamento a respeito das estratégias de organização de recursos competitivos em diferentes tipos de empresas, gerando o enriquecimento da literatura no campo da administração estratégica.

\section{REFERÊNCIAS}

ACCOR HOTELS. Descubra nossas marcas. Disponível em: < http://www.accorhotels.com/ pt-br/brands/index.shtml>. Acesso em: 05 mar. 2017.

ALVES, Simone. Estratégias de Diferenciação em Mercados Maduros: Um olhar a partir do Segmento de Serviços de Hotelaria. Sistemas \& Gestão, v. 6, n. 2, p.130-145, 2011.

BARDIN, Laurence. Análise de Conteúdo. São Paulo: Edições 70, 2011.

BARNEY, J. B. Firm resources and sustained competitive advantage. Journal of Management, v. 17, n. 1, p. 99-120, 1991.

BARNEY, Jay B. Evaluating Firm Strengths and Weaknesses: The Resource-based View. In: BARNEY, Jay B. Gaining and Sustaining Competitive Advantage. 3. ed. New Jersey: Prentice-Hall, 2002. Cap. 5. p. 149-185.

BARNEY, Jay B.; HESTERLY, William S. Avaliação das capacidades internas de uma empresa. In: BARNEY, Jay B.; HESTERLY, William S.. Administração estratégica e vantagem competitiva. São Paulo: Pearson Prentice Hall, 2007. Cap. 3. p. 63-97. Tradução de: Monica Rosemberg.

BONI, Valdete; QUARESMA, Sílvia J. Aprendendo a entrevistar: como fazer entrevistas em Ciências Sociais. Em Tese, v. 2, n. 1, p. 68-80, 2005. 
BUZZERIO, Felipe G.; MARCONDES, Reynaldo C. A Inteligência Competitiva na perspectiva de ser uma fonte de vantagem competitiva e suas contribuições estratégicas . Revista de Ciências da Administração, v. 16, n. 40, p. 235-249, 2014.

CAMARGO, Álvaro A. B. de; ZILBER, Moisés A. Verificação de vantagem competitiva em empresas brasileiras de tecnologia com base no modelo de pedras angulares de Peteraf. Gestão e Regionalidade, v. 29, n. 85, p.5-17, abr. 2013.

CARDEAL, Nuno; ANTÓNIO, Nelson. Valuable, rare, inimitable resources and organization (VRIO) resources or valuable, rare, inimitable resources (VRI) capabilities: What leads to competitive advantage? Afr. J. Bus. Manage, v. 6, n. 37, p.10159-10170, set. 2012.

CRUBELLATE, João Marcelo; PASCUCCI, Lucilaine; GRAVE, Paulo Sérgio. Contribuições para uma visão baseada em recursos legítimos. Revista de Administração de Empresas, São Paulo, v. 48, n. 4, p.8-19, dez. 2008.

DIEHL, Astor A. ; TATIM, Denise C. Metodologia, método e técnicas de pesquisa. In: DIEHL, Astor A. ; TATIM, Denise C. Pesquisa em ciências sociais aplicadas: Métodos e técnicas. São Paulo: Pearson, 2004. Cap. 4. p. 47-88.

EISENHARDT, Kathleen M. Building theories from case studies research. Academy Management Review, v. 14, n. 4, p. 532-550, 1989.

GONÇALVES, Carlos A.; COELHO, Mariana de F.; SOUZA, Érika M. de. VRIO: Vantagem competitiva sustentável pela organização. Revista Ciências Administrativas, Fortaleza, v. 17, n. 3, p.819-855, dez. 2011.

GRANT, Robert M. The Resource-Based Theory of Competitive Advantage: Implications for Strategy Formulation. California Management Review, v. 33, n. 3, p.114-135, abr. 1991. University of California Press.

HAYASHI JR, Paulo; ABIB, Gustavo; BOUSCHEID, Maria M. O uso estratégico de recursos e capacidades no setor hoteleiro: O caso Ritz Porto Alegre. Pasos: Revista de Turismo y Patrimonio Cultural, v. 12, n. 2, p.315-324, 2014.

JOÃO, Belmiro do N. et al. Inovação de valor: o caso Citizenm Hotels. Revista Turismo Visão e Ação, v. 13, n. 3, p.299-310, dez. 2011.

KNOTT, Paul. Integrating resource-based theory in a practice-relevant form. Journal Of Strategy And Management, v. 2, n. 2, p.163-174, 2009.

KRETZER, Jucélio; MENEZES, Emílio A. A importância da Visão Baseada em Recursos na explicação da vantagem competitiva. Revista de Economia Mackenzie, v. 4, n. 4, p.63-87, 2006.

LEITE, Yákara V. P.; PRIMO, Marcos A. M. Cadeias globais: uma contribuição da RBV no processo de internacionalização. Produto \& Produção, v. 15, n. 1, p.10-21, fev. 2014.

LEMOS, L. R.; TORTATO, U. Canais de distribuição e vantagem competitiva sustentável: uma análise baseada em recursos da firma. Revista Brasileira de Estratégia, v. 2, n. 2, p. 121-132, 2009.

MARTINS, Tomas S. et al. Escolhas Estratégias e Capacidades Dinâmicas na Hotelaria. In: ENCONTRO DA ANPAD, 37. 2013, Rio de Janeiro. Anais... . Rio de Janeiro: Anpad, 2013. p. $1-16$. 
MORESCO, Marcielly C.; MARCHIORI, Marlene; GOUVEA, Daniela M. R. Pensamento estratégico e planejamento estratégico: possíveis inter-relações. Revista Gestão \& Planejamento, Salvador, v. 15, n. 1, p. 63-79, 2014.

NEVES, José L. Pesquisa qualitativa: características, usos e possibilidades. Caderno de Pesquisas em Administração,São Paulo, v. 1, n. 3, p.1-5, jun. 2006.

OKUMUS, Fevzi; ROPER, Angela. A Review of disparate approaches to strategy implementation in hospitality firms. Journal Of Hospitality \& Tourism Research. p. 21-39. fev. 1999.

OLIVEIRA, Paulo H.; GONÇALVES, Carlos A.; PAULA, Edmar A. M. Uma Visão baseada em Recursos da Inteligência Competitiva. Revista de Ciências da Administração, v. 15, n. 35, p. 141-151, 2013.

OLSEN, Michael D.; ROPER, Angela. Research in strategic management in the hospitality industry. International Journal of Hospitality Management, v. 17, n. 2, p. 111-124, 1998.

OLSEN, Michael D.; TSE, Eliza Ching-Yick; WEST, Joseph J. Strategic Management in the Hospitality Industry. 2. ed. John Wiley \& Sons, Inc., 1998. p. 1-44; 173-204.

PAVÃO, Yeda M. P.; SEHNEM, Simone; HOFFMANN, Valmir E. Análise dos recursos organizacionais que sustentam a vantagem competitiva. Revista de Administração, São Paulo, v. 46, n. 3, p. 228-242, set. 2011.

PETERAF, M. A. The cornerstones of competitive advantage: a resource-based view. Strategic Management Journal, v.14, n. 3, p. 179-191, 1993.

POMPERMAYER, Cleonice B. Sistemas de gestão de custos: dificuldades na implantação. Revista da FAE, v. 2, n. 3, 2017.

PORTER, Michael E. O que é estratégia. In: PORTER, Michael E. Competição on competition: Estratégias competitivas essenciais. 2. ed. Rio de Janeiro: Campus, 1999. Cap. 2. p. 46-82.

PRAHALAD, C.K. The role of core competencies in the corporation. Research Technology Management. v. 36, n. 6, p. 40-47, 1993.

RIBEIRO, Henrique C. M. et al. Visão baseada em recursos: uma análise bibliométrica dos últimos 11 anos. Revista de Ciências da Administração, v. 14, n. 34, p. 39-59, 2012.

SALAZAR, Viviane S.; MORAES, Walter F. A. de; LEITE, Yákara V. P. Chamem o Chef! O Principal Recurso Estratégico Dos Restaurantes Gastronômicos: Estudo de Multicasos na América Latina. In: ENCONTRO DE ESTUDOS EM ESTRATÉGIA, 7. 2015, Brasília. Anais... . Brasília: Anpad, 2015. p. 1 - 16.

SALGADO, Camila C. R.; COLOMBO, Ciliana R. Sistema de gestão ambiental no Verdegreen Hotel - João Pessoa/PB: Um estudo de caso sob a perspectiva da Resource-Based View. Revista de Administração Mackenzie, São Paulo, v. 5, n. 16, p.195-225, out. 2015.

SANEMATSU, L.; SILVA, A.; VIEIRA, A. Relação entre Fabricante e Varejista: um Estudo Qualitativo Comparativo no Setor de Peças Automotivas. NAVUS - Revista de Gestão e Tecnologia, v. 6, n. 3, p. 56-69, 2016.

SANTOS, Luciano C. et al. Como dar suporte às estratégias de empresas hoteleiras? Uma análise segundo a visão baseada em recursos. Production, v. 25, n. 2, p.403-415, jun. 2015. 
SANTOS, Luciano C.; GOHR, Cláudia F.; CRUZ, Igor K. H. Avaliação de recursos estratégicos em empresas hoteleiras de um município sul-mato-grossense. Rebrae: Revista Brasileira de Estratégia, Curitiba, v. 4, n. 3, p.231-243, dez. 2011.

SILVA, Antônio J. H. da; TEIXEIRA, Rivanda M. Recursos internos como diferenciais competitivos aplicados ao processo de adaptação estratégica em empresas do setor hoteleiro de Curitiba: estudo comparativo de casos. Latin American Journal Of Business Manegement, Taubaté, v. 1, n. 1, p.119-145, jun. 2010.

TEECE, D. J.; PISANO, Gary; SHUEN, Amy. Dynamic capabilities \& strategic management. Oxford: Oxford University Press, v. 18, n. 7, p. 509-533, 1997.

VALLANDRO, Luiz F. J.; TREZ, Guilherme. Visão baseada em recursos, estratégia, estrutura e performance da firma: uma análise das lacunas e oportunidades de pesquisas existentes no campo da administração estratégica. Análise - Revista de Administração da PUCRS, v. 24, n. 1, p. 79-81, jul. 2013.

VASCONCELOS, Flávio C.; CYRINO, Álvaro B. Vantagem competitiva: os modelos teóricos atuais e a convergência entre estratégia e teoria organizacional. Revista de Administração de Empresas, São Paulo, v. 40, n. 4, p. 20-37, 2000.

SANEMATSU, L.; SILVA, A.; VIEIRA, A. Relação entre Fabricante e Varejista: um Estudo Qualitativo Comparativo no Setor de Peças Automotivas. NAVUS - Revista de Gestão e Tecnologia, v. 6, n. 3, p. 56-69, 2016.

Recebido em: 11-8-2017

Aprovado em: 16-11-2020

Avaliado pelo sistema double blind review.

Editor: Coordenação do PPGA/UMESP

Disponível em http://mjs.metodista.br/index.php/roc 